\title{
LINGUAGEM E DEFICIÊNCIA: POSSIBILIDADES E RESTRIÇÕES DA PRÁTICA FONOAUDIOLÓGICA
}

\author{
Débora Dainêz* \\ Maria Inês Bacellar Monteiro" \\ Ana Paula de Freitas \\ Carolina Ávila Cisotto ${ }^{\Phi}$
}

\begin{abstract}
RESUMO. A partir de pressupostos da teoria histórico-cultural, neste texto tem-se o objetivo de refletir sobre a linguagem de sujeitos com deficiência mental. Os dados foram extraídos de transcrições de filmagens de um ano de atendimento fonoaudiológico semanal do qual participavam duas estagiárias de fonoaudiologia e quatro jovens deficientes mentais com idades entre 19 e 29 anos. As interações de um dos jovens com seus pares e terapeutas foram focalizadas no estudo. Os resultados indicaram que em alguns momentos os terapeutas e pares fizeram interpretações que levaram à compreensão do intuito comunicativo do sujeito, mas em outros isto não ocorreu e o diálogo foi interrompido. Discute-se a importância do outro para a construção de sentidos e para a orientação de ações terapêuticas e educativas que criem possibilidades alternativas de linguagem. Considera-se que um olhar mais atento para compreender o intuito comunicativo de sujeitos deficientes pode auxiliar no desenvolvimento dessas pessoas.
\end{abstract}

Palavras-chave: abordagem histórico-cultural; deficiência mental; intervenção fonoaudiológica.

\section{LANGUAGE AND MENTAL DEFICIENCY: SPEECH THERAPY POSSIBILITIES AND RESTRICTIONS}

\begin{abstract}
Based on the historical-cultural theory assumptions we herein aim to reflect on mentally deficient subjects' language. The data were collected from video recording transcriptions along one year of weekly speech therapy sessions, with the participation of two speech therapy interns and four youngsters with mental deficiency, aged between 19 and 29 . We focused on the interactions of one of the youngsters with his peers and therapists. The results revealed that at some moments the therapists' and the peers' interpretation led to the understanding of the communicative intention. However, there were moments when such understanding didn't occur and the dialogue was interrupted. The importance of the other for building up meaning and guiding therapeutic actions which can promote the creation of language alternatives is here discussed. Therefore, it is considered that a more attentive look to understand the communicative purposes of subjects with mental deficiency can enhance their development.
\end{abstract}

Key words: Historical-Cultural Approach; mental deficiency; speech therapy intervention.

\section{LENGUAJE Y DISCAPACIDAD: POSIBILIDADES Y RESTRICCIONES DE LA PRÁCTICA FONOAUDIOLÓGICA}

RESUMEN. A partir de suposiciones de la teoría histórico-cultural, en este texto se tiene el objetivo de reflexionar sobre el lenguaje de sujetos con discapacidad mental. Los datos fueron extraídos de transcripciones de películas referentes a un año de atendimiento fonoaudiológico semanal, del cual participaban dos estudiantes en práctica de fonoaudiología y cuatro jóvenes discapacitados mentales con edad entre 19 y 29 años. Las interacciones de uno de los jóvenes con sus semejantes y terapeutas fueron focalizadas en el estudio. Los resultados indicaron que en algunos momentos los terapeutas y semejantes hicieron interpretaciones que condujeron a la comprensión del intuito comunicativo del mismo, sin embargo, en otros, esto no ocurrió y el diálogo fue interrumpido. Se discutió la importancia del otro para la construcción de sentidos y para la orientación de

\footnotetext{
Mestre em Educação pela Universidade Metodista de Piracicaba.

II Doutora em Psicologia e Docente do Programa de Pós-Graduação da UNIMEP.

æ Dourtora em Educação e Docente do Curso de Fonoaudiologia da UNIMEP.

$\Phi$ Graduada em Fonoaudiologia pela UNIMEP.
} 
acciones terapéuticas y educativas que crean posibilidades alternativas de lenguaje. Se considera que una observación más atenta para comprender el intuito comunicativo de sujetos discapacitados puede auxiliar al desarrollo de estas personas.

Palabras-clave: Abordaje Histórico-Cultural; discapacidad mental; intervención fonoaudiológica.

Este estudo pauta-se no interesse pela compreensão de processos de desenvolvimento da linguagem de sujeitos com deficiência mental que apresentam singularidades em seu funcionamento. $\mathrm{O}$ estudo apoia-se na matriz histórico-cultural, que tem como seu principal representante Vigotski (1997, 2001, 2003).

Inicialmente são apresentados conceitos importantes dessa teoria, relacionados à linguagem, ao desenvolvimento e aos estudos do autor sobre a deficiência mental.

Vigotski (2001) concebe a linguagem como signo exclusivamente humano que duplica o mundo perceptível, permitindo ao homem a capacidade de abstração e generalização. A linguagem verbal é a principal instância na comunicação entre os membros do grupo social e é também responsável pela formação do pensamento e da consciência. Assim, o autor atribui um papel fundamental na constituição do sujeito à linguagem e à interação social, as quais têm uma importância crucial no desenvolvimento humano.

Segundo essa teoria, a constituição do sujeito tem gênese social, ou seja, é sempre o outro que atribui sentido à fala e ações da criança, através de um processo semioticamente mediado. A criança vai se desenvolvendo nas relações com os indivíduos do seu grupo social não de uma maneira linear, mas com a compreensão das transformações que avançam para aquilo que é novo a partir do que foi anteriormente constituído. Para Vigotski (2003), todas as funções especificamente humanas são constituídas por meio da vida social, portanto envolve a linguagem e a dimensão histórico-cultural.

Visto isso, ao examinar o funcionamento da linguagem de jovens com deficiência mental, este estudo preocupa-se com a inter-relação do contexto social com a constituição dos processos psíquicos.

Góes (2000, 2008), ancorada nos pressupostos de Vigotski, ressalta como fator fundamental nas relações do indivíduo com o grupo social a linguagem, cuja função é regular as ações e propiciar as condutas de relações humanas. "A palavra tem o poder de regular e de conferir um caráter mediador à relação entre as pessoas" (Góes, 2000, p. 121). Deste modo, as interações verbais e dialógicas são apropriadas e reconstruídas no plano intrapessoal, fazendo parte da constituição social da personalidade do sujeito. Os significados vão sendo construídos por meio da mediação semiótica (mediação simbólica) nas relações com as pessoas, por meio da linguagem e de suas mais diversas expressões.

As ideias discutidas na teoria histórico-cultural sobre a interação sujeito-meio/outro e a constituição/desenvolvimento cultural dão uma base substantiva para o estudo de processos que afetam o funcionamento humano de sujeitos com deficiência.

Sobre esta questão, Góes (2008) argumenta que é preciso cautela ao se compreender o papel do grupo social na interação sujeito-meio-outro. A idéia fundamental que a autora desenvolve é que "o sujeito é na vida social, e que, portanto, suas possibilidades de desenvolvimento estão nele e noutros membros da cultura em que vive" (Góes, 2008, p. 38). Portanto, não se trata de compreender o grupo social como um fator exterior ao sujeito, mas como constituinte do seu modo de ser humano.

Para melhor compreensão das possibilidades de desenvolvimento de pessoas com deficiência, este texto discute as questões levantadas por Vigotski (1997) na sua obra "Fundamentos da defectologia", em relação aos modos de funcionamento psíquico de indivíduos com deficiência mental. Embora seus trabalhos tenham sido produzidos entre a década de 20 e a de 30, suas proposições, em geral, demonstram um ar de contemporaneidade, o que contribui para a construção de caminhos inovadores no âmbito dos atendimentos terapêuticos e ações educacionais em indivíduos com deficiência mental.

Em sua obra Vigotski afirma que a criança cujo desenvolvimento está comprometido por algum tipo de déficit não é, necessariamente, menos desenvolvida que seus pares normais; é apenas uma criança que se desenvolve de outro modo. Para o autor, o que importa não é a deficiência em si mesma, mas é fundamental saber como a criança se desenvolve e como se comporta durante o processo de desenvolvimento em resposta às dificuldades que enfrenta; em outras palavras, é preciso indagar sobre o lugar que essa deficiência ocupa no desenvolvimento e na personalidade desse sujeito, e ainda como este lida e luta contra ela. Neste sentido, se por um lado há sintomas de alteração das funções, por outro há meios e formas de luta do indivíduo contra tais alterações, o que pode possibilitar o encontro de recursos para superar as dificuldades impostas pela deficiência. Observa-se que suas análises buscam centrar-se nos 
processos edificadores da personalidade diante da deficiência.

$\mathrm{Na}$ concepção vigotskiana, o déficit exerce dupla influência no desenvolvimento da criança: ao mesmo tempo em que traz limitações, impulsiona esta para frente, buscando soluções adaptativas nas suas relações sociais no sentido de favorecer a construção da personalidade e da subjetividade. Assim a criança, ao se deparar com alguma dificuldade, tem a possibilidade de avançar por uma via indireta para vencê-la. As dificuldades enfrentadas pela criança deficiente são motivo para o surgimento dos processos de compensação.

$\mathrm{O}$ processo de compensação se relaciona ao funcionamento psicológico, numa ideia que corresponde à plasticidade dos processos de desenvolvimento. Entende-se a compensação enquanto ideia de reorganização funcional da estrutura psíquica, uma vez que a personalidade da pessoa não é uma mera soma de funções insuficientemente desenvolvidas. Isto implica considerar que as funções mentais superiores, como a memória, a atenção, a percepção, a linguagem, como observa Vigotski (2003), relacionam-se a um nível superior e constituem um sistema complexo, dinâmico e integrado.

Considerando-se essa peculiaridade qualitativa da atividade mental, as funções superiores não podem ser afetadas na mesma medida. "A interdependência relativa das funções, em que pese a sua unidade, faz com que o desenvolvimento de uma função compense e redunde em outra" (Vigotski, 1997, p. 141). Desta maneira, as funções mentais são interfuncionais, se transformam em forma de refinamento e envolvem um jogo de inter-relações. Isso implica um dinamismo das formas de funcionamento psíquico no qual as funções afetadas não são da mesma forma, influindo de maneira qualitativamente distinta em sua base.

De Carlo (2001) mostra que o que diferencia uma criança deficiente de uma tida como normal é o tipo de estrutura orgânica e psicológica, e não padrões quantitativos. Nesta perspectiva, há revoluções qualitativas relacionadas com a aparição de formas novas ou até mais avançadas de mediação instrumental e semiótica. Este processo depende tanto da gravidade do quadro orgânico como das dificuldades inerentes à posição social. "A cultura provoca uma reelaboração da conduta natural da criança e um redirecionamento do curso do desenvolvimento, sob novas condições e sobre novos fundamentos" (De Carlo, 2001, p. 67).

Vigotski (1997) propõe que a deficiência tem um caráter mais social que biológico, ainda que este último não possa ser desprezado. A base da deficiência mental é formada pela esfera biológica, no entanto as características particulares se formam de acordo com as relações interpessoais no meio social, que podem possibilitar ou não formas de superação das restrições biológicas.

Em relação a isso, Carvalho (2006) comenta que as dificuldades surgidas no plano das funções elementares serão transformadas por formas alternativas de ação que se caracterizam tanto como formas positivas de desenvolvimento quanto como dificuldades maiores.

Dainêz (2009) focaliza a noção de compensação a partir do acompanhamento de duas crianças com deficiência mental inseridas no Ensino Fundamental da rede regular de ensino. A autora observa que os educadores oportunizam experiências minimizadas e destituídas de sentido para os alunos com deficiência mental; segundo ela, o desenvolvimento da criança deficiente deve ser considerado dentro da esfera simbólica, na qual a palavra é tida como signo mediador das ações e relações humanas, permitindo a significação do mundo. Assim, a autora relembra nas suas discussões o fato de que os signos desempenham papel organizador da resposta, controlando a ação do indivíduo humano.

Góes (2007) aborda aspectos do desenvolvimento de sujeitos com deficiência e analisa as condições educacionais oferecidas a esses sujeitos, e para isso destaca as contribuições da corrente histórico-cultural. Afirma que o desenvolvimento do indivíduo se constitui a partir da qualidade das vivências sociais e culturais que lhe são propiciadas. Isto significa que não é o déficit orgânico em si que traça o destino da criança, e sim, o modo como a deficiência é significada pelas formas de cuidado e educação recebidas pela criança.

A autora se refere a Vigotski quando afirma ser necessário considerar que o modo de vida da sociedade está arranjado para as condições do desenvolvimento humano típico que caracteriza o geral, quando a criança tem órgãos ilesos e com condições de intelecto; já os sujeitos que possuem deficiência mental têm problemas quando inseridos nesse social. A autora considera a necessidade de criar formas culturais singulares que permitam explorar caminhos alternativos de desenvolvimento, o que implica o uso de recursos especiais.

Castro (2010) estudou o processo de interação comunicativa de duas crianças com comportamentos autísticos associados à Síndrome de Down. As crianças foram observadas durante atendimento fonoaudiológico realizado em dupla, nas situações de 
brincadeiras de faz-de-conta. A autora constatou que proporcionar às crianças oportunidades terapêuticas para a superação de suas dificuldades permitiu que estas mostrassem condições de se constituírem como sujeitos sociais comunicativos, em contextos interativos.

Assim, os estudos citados acima chamam a atenção para a substituição de uma via de ação por outra. Apontam para a necessidade de procurar formas e possibilitar vias possíveis para que o indivíduo ultrapasse seus limites.

Além dos aspectos fundamentais, descritos acima, relacionados à abordagem histórico-cultural, considera-se importante destacar alguns estudos que abordam o tema da grupoterapia ou do funcionamento de grupos, à medida que a inserção de sujeitos com deficiência mental em situações privilegiadas de interação (como é o caso do grupo terapêutico) pode possibilitar o uso da linguagem de maneira plena e efetiva.

Pesquisas sobre o trabalho fonoaudiológico em grupo indicam uma possibilidade maior de desenvolvimento da linguagem, uma vez que as interações entre os sujeitos criam um ambiente favorável para a interação e significação (Oliveira \& Camargo, 2007).

O grupo, na clínica fonoaudiológica, pode ser um espaço rico para a constituição do sujeito e para o desenvolvimento da linguagem, pois permite explorar os dizeres de cada um em contextos naturais de funcionamento. Neste microcosmo podem ser destacados os valores culturais do grupo e do próprio sujeito participante, mas isto não exclui a necessidade de ampliação da clínica para outros espaços sociais relacionados à vida do sujeito, como a família e a escola.

Segundo Oliveira e Camargo (2007), a linguagem na clínica fonoaudiológica, que funciona como atividade mediadora, possibilita interações e ações do meio social em que participam a terapeuta, o paciente e a família. Deste modo, o objetivo primordial da clínica fonoaudiológica é fornecer instrumentos (signos) ao paciente e sua família para que sejam capazes de construir, através da linguagem, sua própria história e que estes ocupem um lugar social.

As contribuições dos estudos relacionados acima são relevantes, pois eles ajudam a entender algumas vias importantes para a compreensão da linguagem em seu funcionamento e, mais especificamente, a pensar em formas de intervir e promover condições mais favoráveis e significativas para a transformação do desenvolvimento ante a existência de um problema de ordem biológica. Ao contrário do que ocorre na clínica tradicional, o olhar do terapeuta desloca-se do orgânico e do individual para condições sociais concretas de vida do sujeito, considerando que existem possibilidades de subversão das barreiras sociais e culturais através da palavra e da ação do outro.

\section{MÉTODO}

Como o sujeito se constitui a partir de suas experiências sociais, num processo interativo possibilitado pela linguagem, os procedimentos de pesquisa utilizados permitem uma atenção às minúcias das relações vivenciadas pelo sujeito deficiente mental na situação de atendimento de linguagem no grupo terapêutico-fonoaudiológico.

Acredita-se que detalhes das relações à primeira vista insignificantes podem revelar aspectos importantes do funcionamento e das transformações das ações dos sujeitos.

Esta opção metodológica permite o estudo do processo em sua dimensão histórica, o que foi defendido por Vigotski (2001, 2003) como essencial para a compreensão do funcionamento humano.

Adota-se assim a abordagem metodológica referida como análise microgenética, que, segundo Góes (2000), permite a construção de dados considerando os indícios dos acontecimentos, os detalhes e o recorte de episódios interativos, sendo o exame orientado para o funcionamento dos sujeitos, as relações intersubjetivas e as condições sociais da situação.

Para a autora, a análise microgenética caracterizase por uma atenção às minúcias de um processo, de modo a configurar sua gênese social e as transformações do curso de eventos. Essa análise é voltada para a busca da compreensão do desenrolar das ações do sujeito e para a explicação de suas construções e transformações cognitivas. Conforme Góes, "essa análise não é micro porque se refere à curta duração dos eventos, mas sim por ser orientada para minúcias indiciais - daí resulta a necessidade de recortes num tempo que tende a ser restrito" (Góes, 2000, p.15). Ela identifica transformações nas ações dos sujeitos e a passagem do funcionamento intersubjetivo para o intrassubjetivo. Também há uma preocupação em relacionar os eventos singulares com outros planos da cultura e das práticas sociais.

$\mathrm{O}$ estudo foi realizado em uma clínica de fonoaudiologia vinculada a um curso de fonoaudiologia de uma universidade particular do interior do Estado de São Paulo. Nesse local, duas estagiárias e uma docente do curso atendiam 
semanalmente um grupo com quatro jovens (An., Gi., Ed. e Cl.) do sexo masculino cujas idades variavam entre 19 e 29 anos, todos com diagnóstico de deficiência mental.

Os jovens apresentavam alterações de linguagem, sendo que Gi. e Ed. comunicavam-se por gestos indicativos e representativos e algumas poucas palavras; An. e Cl. apresentavam uma oralidade mais desenvolvida, com alterações discursivas, como, por exemplo, não olhar para o interlocutor enquanto fala e não tomar a iniciativa durante o diálogo, além de algumas trocas articulatórias. Neste texto elege-se o sujeito Ed. como foco de análise, pois ele é um jovem que geralmente usa gestos para se comunicar e, efetivamente, necessita mais da ajuda dos interlocutores para se fazer entender. Os jovens An. Gi. e Cl. estavam presentes na sessão fonoaudiológica relatada, mas não participavam da dinâmica dialógica no trecho recortado para a análise.

$\mathrm{O}$ instrumento para registro de dados foi a videogravação, a qual foi realizada no ano de 2006, entre os meses de agosto a novembro. O material foi transcrito ortograficamente. A partir das transcrições foi selecionada para análise uma situação com foco no sujeito Ed. a qual apresentava indícios de como o processo dialógico estava fluindo.

Os dados foram analisados mediante o exame pormenorizado de turno por turno da fala de cada participante, com o intuito de identificar os episódios nos quais os componentes do grupo manifestavam seus sentimentos sobre sua própria imagem e história. De acordo com Marcuschi (2007), os turnos conversacionais se referem "(...) aquilo que um falante faz ou diz enquanto tem a palavra, incluindo aí a possibilidade do silêncio" (Marcuschi, 2007, p. 18).

A análise buscou caracterizar os recursos utilizados pelos sujeitos para se fazerem entender pelo grupo e a atuação do terapeuta na dinâmica dialógica. No episódio apresentado, destacam-se as possibilidades comunicativas utilizadas pelo sujeito Ed.

\section{RESULTADOS E DISCUSSÕES}

O dado apresentado a seguir refere-se a uma situação vivida no primeiro dia de atendimento do anona qual as novas terapeutas estavam conhecendo o grupo. As terapeutas propuseram uma atividade ${ }^{1}$ que permitia a apresentação de cada um para o grupo. $\mathrm{O}$

1 Dinâmica do "barbante": Um dos participantes do grupo segura um rolo de barbante e, à medida que se apresenta, desenrola um pedaço do barbante, joga para outro e, assim, sucessivamente. objetivo das terapeutas era realizar uma conversa entre todos do grupo, a fim de proporcionar uma interação dialógica $^{2}$ entre os sujeitos. As terapeutas se posicionavam de maneira a procurar dar significado ao intuito discursivo dos sujeitos.

No episódio Ed. está procurando encontrar um caminho para responder à pergunta feita pela terapeuta sobre sua idade.

Turno 1 T1: Vamos ver se a gente consegue. Vou começar, hein! Meu nome é Ma, eu vou ser a terapeuta de vocês. Vocês gostam de vir na fono? Vocês estavam com saudade? Depois vocês vão contar das outras meninas que atenderam vocês, tá? Então vai, oh eu vou jogar. Segura (neste momento T1 joga o barbante para o sujeito Ed)! Agora é você que fala: fala seu nome, se você gostava de vir aqui, como que era (referindo-se a Ed).

Turno 2 T2: O que você gostava de fazer aqui?

Turno 3 T1: É.

Turno 4 Ed: (Segurando o barbante, aponta para baixo e estala os dedos, como se estivesse indicando que faz tempo que participa do grupo).

Turno 5 T1: Faz tempo?

Turno 6 Ed: (Afirma com a cabeça).

Turno 7 T1: Que legal e o seu nome?

Turno 8 Ed: Ed.

Turno 9 T1: Ed?

Turno 10 Ed: (Afirma com a cabeça).

Turno 11 T2: Ah, legal! Quantos anos o Ed tem?

Turno 12 Ed: (Levanta a mão indicando cinco).

Turno 13 T2: Você lembra quantos anos o Ed tem? (T2 ignora a resposta dada pelo sujeito e pergunta para $\mathrm{T} 1)$.

Turno 14 T1: Tem na pasta ${ }^{3}$.

Turno 15 T2: Vamos ver que dia que é o aniversário.

\footnotetext{
Compreende-se aqui a interação dialógica como todas as possibilidades comunicativas, sejam elas orais ou não.

3 Prontuário: pasta individual contendo todos os dados (de identificação e clínicos) dos sujeitos atendidos na ClínicaEscola de Fonoaudiologia. O prontuário permanece arquivado na secretaria da clínica.
} 
Turno 16 Ed: (Neste momento Ed entrega a carteirinha de frequência ${ }^{4}$ da terapia fonoaudiológica realizada no ano anterior para T1; esta carteirinha tem dados sobre o atendimento fonoaudiológico do semestre anterior).

Turno 17 T1: Ah, é a carteirinha de frequência! Você trouxe, ah legal!

Turno 18 Ed: Oh! (aponta com o dedo indicador para a carteirinha de frequência que está na mão da T1)

Turno 19 T1: Ah, legal! (lendo os nomes que estão anotados); a Ga e a De (estagiárias que atendiam o grupo anteriormente): ah, legal!

Turno 20 T2: Ah, mas esse ano a gente vai fazer outro cartão.

Turno 21 T1: É a gente vai fazer um outro, tá?

(as terapeutas propõem que Ed jogue o barbante para Gi, outro componente do grupo, e a dinâmica continua. Não se fala mais sobre a idade de Ed).

O episódio acima apresenta uma atividade de interação entre os sujeitos do grupo. $\mathrm{Na}$ análise que segue busca-se localizar pistas que indiquem restrições e possibilidades criadas para a pessoa com deficiência no campo das práticas terapêuticas, por exemplo, quais são as condições de possibilidades de participação de Ed. que se configuram no grupo terapêutico. Ed. utiliza gestos acompanhando ou substituindo as palavras para responder às perguntas feitas pelas terapeutas. Busca vias e caminhos para suprir a dificuldade de expressar-se oralmente. Os gestos parecem funcionar para evocar aquilo que quer contar, ou seja, é outro modo de realização da atividade. Esta é uma alternativa frequentemente utilizada por pessoas com impedimentos temporários ou permanentes da oralidade.

Fedosse e Santana (2002) ressaltam que a relação entre gesto e fala é de interdependência, pelas características simbólicas, cognitivas e interativas que ambos apresentam. As autoras analisam episódios interativos coletados de segmentos terapêuticos com sujeitos afásicos e indicam que "os gestos demonstram os processos alternativos pelos quais os sujeitos lançam mão para demarcar seus modos de operar

Cartão de frequência: é um cartão que fica em posse dos usuários da clínica-escola. Nele constam dados de identificação do sujeito, dados referentes aos tipos de atendimentos realizados, bem como dia e horário desses atendimentos. sobre e na linguagem..." (Fedosse \& Santana, 2002, p. 253).

Observa-se esta compreensão por parte do interlocutor no turno 5, quando a terapeuta interpreta o gesto de apontar para baixo e estalar os dedos como indicativo de que faz tempo que Ed. frequenta a clínica. Fazendo isso, a terapeuta dá significado ao gesto realizado e torna o dizer de Ed acessível ao grupo. Os sentidos vão sendo produzidos nas interações entre sujeitos. A terapeuta explora um caminho promovendo a interação e a participação dialógica do sujeito com dificuldades acentuadas na esfera da linguagem no grupo, o que propicia ao sujeito dizer algo e ser entendido. Assim, as ações do outro abrem novas possibilidades de subversão das barreiras encontradas pelo sujeito em decorrência de suas dificuldades de comunicação oral. Isto significa que o social, aqui na figura da terapeuta, sustenta formas de participação do sujeito numa situação compartilhada.

O grupo social, na figura do terapeuta, abre possibilidades para que o jovem se coloque na dinâmica interativa e dialógica, apesar de suas dificuldades orais de comunicação. Isso aponta para aquilo que Padilha (2000) chama a atenção, ou seja, que as limitações - neste caso da linguagem oral, provocadas por alterações orgânicas - podem ser superadas a partir das relações, significações e mediações do outro, como também podem ser reelaboradas semioticamente por meio das experiências culturais.

Para tanto, torna-se imprescindível identificar e criar formas que possibilitem o funcionamento complexo na deficiência mental, opondo-se às dificuldades e conferindo características peculiares ao desenvolvimento cultural e simbólico do indivíduo com deficiência mental.

Não obstante, nota-se que nem sempre o grupo atua com sucesso nesta direção e o sujeito pode ter dificuldades para ser compreendido, o que cria obstáculos ao prosseguimento do diálogo. No turno 11, por exemplo, a terapeuta se dirige ao sujeito perguntando sua idade, mas desconsidera sua resposta gestual (que indicava com os dedos o número cinco), provavelmente porque a resposta não corresponde à idade real do sujeito (jovem com mais de 20 anos). Aqui se observa o jovem criando e usando um recurso para revelar a idade, qual seja, informar a idade com os números de dedos das mãos. Embora essa forma de revelar a idade seja culturalmente utilizada por qualquer sujeito, a terapeuta não releva essa possibilidade comunicativa usada por ele e tem a ideia de buscar a informação correta no prontuário do 
sujeito, e este, valendo-se da ideia de consultar algum documento, entrega o cartão de frequência.

É interessante notar a emergência de processos imaginários enquanto esfera de funcionamento que vai além dos níveis elementares de ação. Góes e Cruz (2006), ao discutirem a relação entre cognição e imaginação proposta por Vigotski, afirmam que esses processos se interpenetram, sendo que a imaginação é concebida como um nível superior de pensamento. Ed. imagina formas e objetos a fim de se fazer entender pelo grupo. A sua imagin(ação) nasce das condições concretas vivenciadas por esse sujeito, marcadas pela impossibilidade de pronunciar oralmente a sua idade, da necessidade de se colocar no espaço grupal, pelo desejo de ser entendido pelos outros. O sujeito faz um jogo de significados na situação imaginária em relação com as categorias básicas da realidade, atuando sobre ela. Apoia-se num objeto como suporte para sua ação de responder à pergunta colocada pela terapeuta e no sentido que ele mesmo conferiu àquele objeto (situação imaginária); mas, como mostram os turnos 19, 20 e 21, essa ação do sujeito não é compreendida pelas terapeutas como uma estratégia diferenciada, da qual Ed. faz uso, na tentativa de dizer/mostrar/revelar sua idade. Com isso o diálogo toma outro caminho e o assunto sobre a idade de Ed. é esquecido pelo grupo.

Outro aspecto que chama a atenção no turno 11 é a maneira como a terapeuta dirige uma pergunta ao sujeito deficiente: “Quantos anos o Ed. tem?”. Não poderia ela perguntar: "Quantos anos você tem, Ed.?" A terapeuta revela de forma subliminar que não vê possibilidades de o sujeito com deficiência mental responder corretamente sobre sua idade, então lançalhe uma pergunta indireta que o acaba colocando no lugar de um incapaz, como se ele não pudesse entender e responder à questão. Isso é confirmado no turno 13, quando a terapeuta não considera o gesto de Ed realizado no turno 12 na tentativa de resposta e se dirige a outra terapeuta perguntando a idade real de Ed. Com isso, não se pondera o intuito discursivo subjacente à linguagem gestual do sujeito com deficiência mental.

De acordo com Vigotski (1997), as possibilidades de desenvolvimento do indivíduo deficiente só se concretizam se o grupo social não se centrar nos aspectos negativos da deficiência, e sim, no que há de positivo nesse processo.

De Carlo (2001) alerta que não se podem subestimar as pessoas e deter-se em suas incapacidades, é preciso ouvir o que o sujeito deficiente tem a "dizer", sejam quais forem seus recursos comunicativos.
Este episódio revela possibilidades e impossibilidades nas tentativas de um jovem com peculiaridades significativas de linguagem em responder às perguntas/inquietações da terapeuta e participar da dinâmica dialógica e interativa do grupo. De acordo com Vigotski (1997), o outro, através da mediação semiótica/simbólica, tem o papel de conduzir o sujeito deficiente através dos processos de significação.

Ressalta-se a importância do lugar do terapeuta no processo de (re)criação da linguagem do jovem Ed., bem como a natureza não linear do processo de desenvolvimento humano, que vai se construindo e se configurando nas relações estabelecidas com o outro e com o meio social.

\section{CONSIDERAÇÕES FINAIS}

O estudo realizado mostra a importância do papel do outro (terapeuta) no processo de significação da ação e do dizer do indivíduo com deficiência mental, bem como as formas encontradas e os recursos utilizados pelo sujeito com dificuldades de linguagem oral. Mostra também a relevância de pensar o funcionamento psíquico e os processos de desenvolvimento do sujeito com deficiência mental na clínica fonoaudiológica.

Ao examinar o funcionamento da linguagem em um grupo de jovens com deficiência mental, a preocupação central foi a relação entre o contexto social e a constituição dos processos psíquicos.

A partir disso, destaca-se a possibilidade de comunicação de jovens com deficiência mental que possuem problemas de linguagem por outras vias, como o uso de outros recursos envolvidos em interações sociais tendo-se o terapeuta como mediador de todo esse processo.

Nota-se que o grupo, enquanto espaço de interlocução, pode possibilitar ao sujeito deficiente modos diferenciados de relação com o outro e consigo mesmo. Neste espaço as experiências sociais e culturais podem ser vivenciadas e partilhadas. No episódio apresentado, há momentos em que o grupo terapêutico fonoaudiológico oferece condições para que o sujeito avance além de suas dificuldades de linguagem oral e se faça compreendido. Os modos do sujeito foram interpretados pelas terapeutas, que compreenderam seu intuito comunicativo.

Não obstante, há situações em que o outro (terapeuta) não considera as diversas formas do sujeito se expressar, e mesmo não leva em conta o dizer do sujeito, ou seja, não possibilita a significação do diálogo do deficiente. Góes (1997), ao discutir o 
conceito de zona de desenvolvimento proximal no contexto educacional, questiona sobre o lugar conceitual atribuído ao outro e mostra como alguém mais capacitado provoca o desenvolvimento na medida de sua ação. Com isso, enfatiza a importância da atuação do outro no e para o processo de desenvolvimento dos sujeitos, mas deixa claro que esta atuação nem sempre é tranquila. Às vezes, o que se observa são embates na relação, decorrentes de uma baixa qualidade das interações sociais, que não possibilitam o desenvolvimento dos processos internos; todavia, é na complicada dinâmica do funcionamento intersubjetivo que o processo de desenvolvimento deve ser examinado.

As análises realizadas indicam a complexidade da dinâmica em que vai se constituindo o sujeito deficiente no grupo terapêutico, quando se considera que as relações interpessoais são constitutivas de possibilidades de ação psíquica.

Isto significa que os meios usados por sujeitos que apresentam alterações significativas de linguagem devem ser lembrados dentro da clínica fonoaudiológica, pois neste espaço, através das interpretações do terapeuta, as ações realizadas pelos sujeitos com deficiência mental podem ser significadas, valorizadas e interpretadas pelo outro. Entende-se assim a clínica como um espaço que precisa possibilitar instrumentos para ampliação da participação social do sujeito com deficiência mental.

Com base na perspectiva histórico-cultural, os processos de significação concretizam-se na vida cotidiana das pessoas como produção social, nas diferentes formas de práticas sociais, culturais e históricas. Neste sentido, acredita-se que é em direção às operações sígnicas que a atuação/ação terapêutica precisa estar orientada, sendo que os modos de compreender o desenvolvimento de indivíduos com deficiência mental consistem em encontrar signos em todo o percurso de inter-relação social.

Destaca-se que o funcionamento superior do sujeito com deficiência mental provém dos processos sociais que são delineados por formas de mediação. $\mathrm{O}$ trabalho orientado para a operação com signos permite agir sobre as pessoas e sobre si mesmo, produzindo mudanças no outro e em si e, consequentemente, orienta formas novas de desenvolvimento da linguagem. É por meio das interações com o outro e pela mediação semiótica que se dá a reorganização do funcionamento psicológico de pessoas com deficiência.

Espera-se ter apontado, neste estudo, caminhos para a reflexão sobre o desenvolvimento humano comprometido pela deficiência, entendendo-se que as dificuldades, limitações e possibilidades das pessoas com deficiências não são determinadas definitivamente por suas condições e características de natureza biológica, mas estão profundamente marcadas pelas oportunidades oferecidas pelo meio social humano.

De acordo com De Carlo (2001), os terapeutas e educadores defrontam-se não com os fatos biológicos em si, mas com suas consequências sociais e psicológicas. Neste sentido, é importante promover condições mais favoráveis e significativas para a transformação do desenvolvimento.

Visto que é na interação que vão sendo construídos os significados compartilhados, ante a impossibilidade de oralização é preciso explorar as múltiplas formas e os potenciais de linguagem para estabelecer comunicação. Desta forma, não basta apenas tratar os distúrbios da linguagem, são necessários modos terapêuticos e educacionais de atuar capazes de promover a construção imaginaria, o que significa promover o funcionamento psíquico complexo.

\section{REFERÊNCIAS}

Carvalho, M. F. (2006). Educação de jovens e adultos com deficiência mental: inclusão escolar e constituição dos sujeitos. Revista Horizontes, 24(2), 161-171.

Castro, G. S. (2010). O processo de interação comunicativa de duas crianças com Síndrome de Down e comportamentos autísticos. Dissertação de mestrado, Programa de Pós-Graduação em Saúde da Criança e do Adolescente, Faculdade de Ciências Médicas da Universidade Estadual de Campinas, Campinas, SP, Brasil.

Dainêz, D. (2009). A inclusão escolar de crianças com deficiência mental: focalizando a noção de compensação na abordagem histórico-cultural. Dissertação de mestrado, Programa de PósGraduação em Educação, Faculdade de Ciências Humanas da Universidade Metodista de Piracicaba, Piracicaba, São Paulo, Brasil.

De Carlo, M. M. R. do. (2001). Se essa casa fosse nossa...: Instituições e processos de imaginação na educação especial. São Paulo: Plexus.

Fedosse, E., \& Santana, A. P. (2002). Gesto e fala: continuidade ou ruptura? Distúrbios da Comunicação, 13(2), 243-255.

Góes, M. C. R. (1997). As relações intersubjetivas na construção de conhecimentos. In: Góes, M.C. R., \& Smolka, A. L. B. (Org.). A significação nos espaços educacionais: interação social $e$ subjetivação (pp.11-28). Campinas, SP: Papirus.

Góes, M. C. R. (2000). A abordagem microgenética na matriz histórico-cultural: uma perspectiva para o estudo da constituição da subjetividade. Caderno Cedes, 20(50), 09-25.

Góes, M. C. R. (2007). Desafios da inclusão de alunos especiais: a escolarização do aprendiz e sua constituição como pessoa. In: Góes, M. C. R., \& Laplane, A. L. F. (Org.). Políticas e práticas da educação inclusiva (pp. 69 -92). 2a ed. Campinas, SP: Autores Associados. 
Góes, M. C. R. (2008). As contribuições da abordagem históricocultural para a pesquisa em educação especial. In: C. R. Baptista, K. R. M., Caiado, D. M. de Jesus (Orgs.). Educação especial: diálogo e pluralidade (pp. 37-46). Porto Alegre: Mediação.

Góes, M. C. R., Cruz, M. N. (2006). Sentido, significado e conceito: notas sobre as contribuições de Lev Vigotski. Pro-Posições, 17(50), 31-45.

Marcuschi, L. A. (2007). Análise da conversação. São Paulo: Ática.

Oliveira, L. G. de, \& Camargo, E. A. A. (2007). A linguagem na clínica fonoaudiológica em crianças com atraso de linguagem. Revista FAEEBA, 16, 209-220.

Padilha, A. M. L. (2000). Práticas educativas: perspectivas que se abrem para a educação especial. Educação \&Sociedade, 21(71), 197-219.
Vigotski, L. S. (2001). A construção do pensamento e da linguagem. São Paulo: Martins Fontes.

Vigotski, L. S. (2003). A formação social da mente. São Paulo: Martins Fontes.

Vygotski, L. S. (1997) Fundamentos da defectologia. Obras Completas. Tomo 5. Madri: Visor.

Endereço para correspondência:

Débora Dainêz. Rua Hermantino Coelho, 77, Bloco 2 - Apartamento 94, Bairro Mansões Santo Antônio, CEP 13.087-500, Campinas-SP, Brasil.E-mail: ddainez@ yahoo.com.br. 